\title{
Robust Hybrid Omniphobic Surface for Stain Resistance
}

Zhengfeng $M a^{a b}$, Yang $W u^{b c^{*}}$, Rongnian $X u^{b}$, Zhihuan ${ }^{d}{ }^{d}$, Yubo Liu ${ }^{b, c}$, Jianxi Liu ${ }^{d}$, Meirong Cai ${ }^{b}$, Weifeng $\mathrm{Bu}^{* a}$ and Feng Zhou ${ }^{b}$

a. State Key Laboratory of Applied Organic Chemistry, Key Laboratory of Nonferrous Metals Chemistry and Resources Utilization of Gansu Province, and College of Chemistry and Chemical Engineering, Lanzhou University, Lanzhou, 730000, PR China

b. State Key Laboratory of Solid Lubrication, Lanzhou Institute of Chemical Physics, Chinese Academy of Sciences, Gansu Lanzhou 730000, PR China.

c. Qingdao Centre of Resource Chemistry and New Materials, Shandong, Qingdao 266100, PR China.

d. State Key Laboratory of Solidification Processing, Centre of Advanced Lubrication and Seal Materials, Northwestern Polytechnical University, Xi'an, Shaanxi, 710072, PR China. 


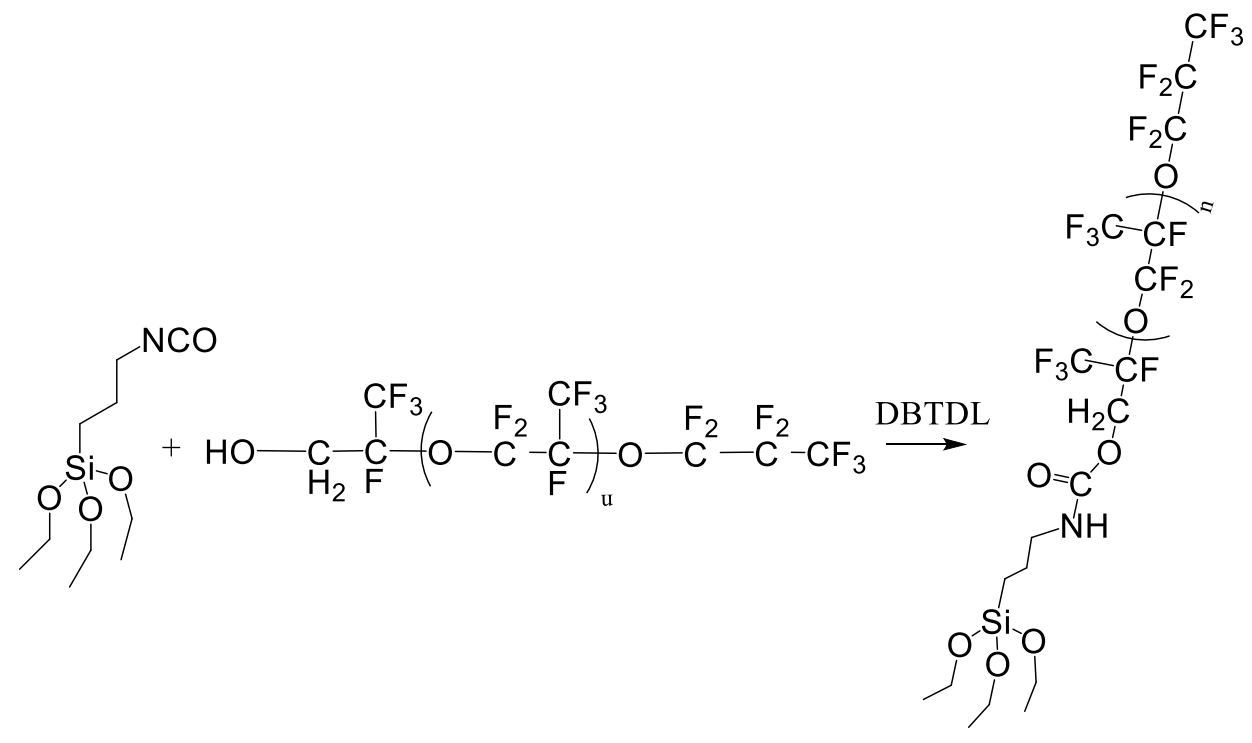

Figure S1. The chemical equation of perfluoropolyether triethoxysilane.
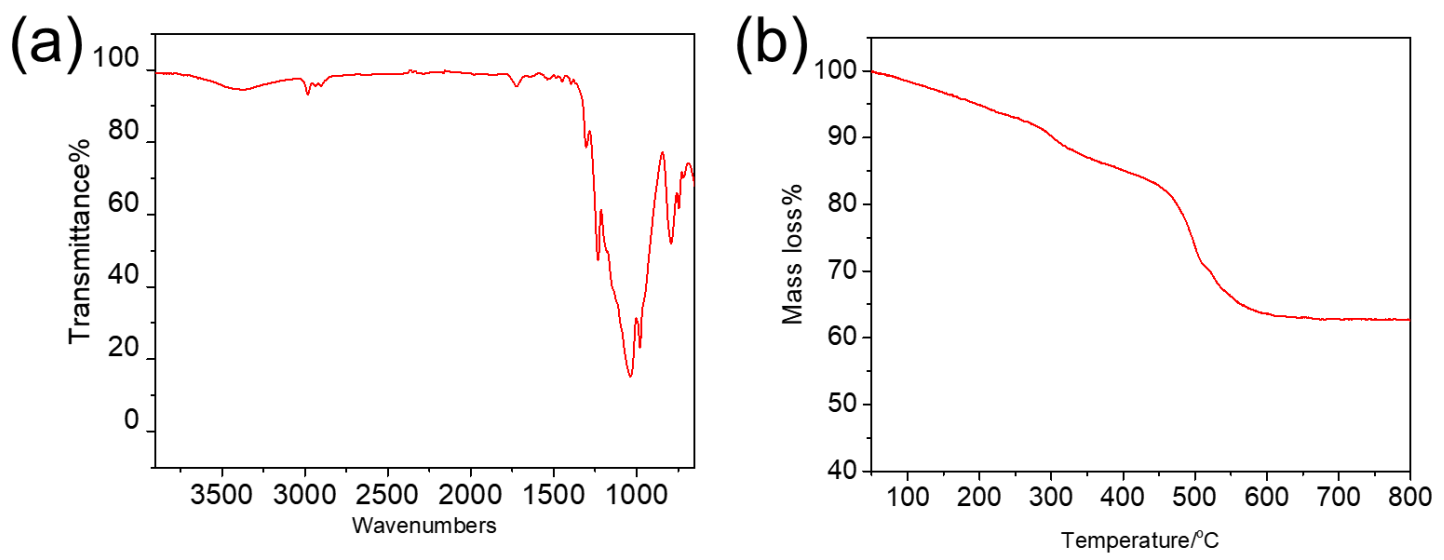

Figure S2. The (a) IR and (b) TG of hybrid coating compound. The peaks at $2982 \mathrm{~cm}^{-1}, 2900 \mathrm{~cm}^{-1}$ were attributed to the stretching vibration of alkyl groups of DBTDL. The peak at $1724 \mathrm{~cm}^{-1}$ corresponded to the stretching vibration of NH-COO group. The peaks at $1308 \mathrm{~cm}^{-1}, 1234 \mathrm{~cm}^{-1}$ were attributed to the stretching vibration of C-F bond, $973 \mathrm{~cm}^{-1}$ was assigned to the stretching vibration of C-O-C bond. $1039 \mathrm{~cm}^{-1}, 790 \mathrm{~cm}^{-1}$ can attribute to the stretching and bending vibration of O-Si-O bond, respectively. From the TG curve of hybrid coating compound, we concluded that the hybrid coating compound thermal decomposed completely until $535^{\circ} \mathrm{C}$ and the content of organic component (PFPE) of hybrid coating compound is about $36.6 \mathrm{wt} \%$. 


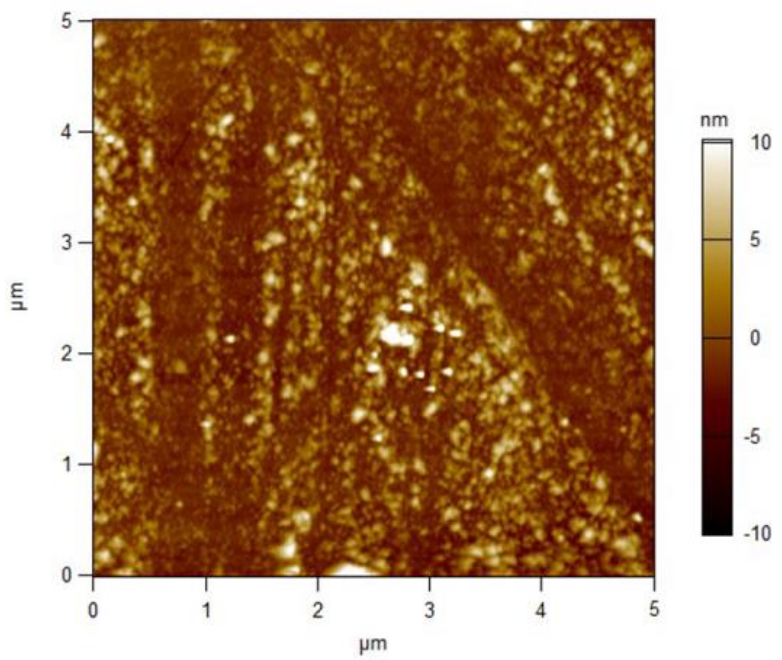

Figure S3. AFM image of raw glass surface. There are many random nano-defects on the glass surface.

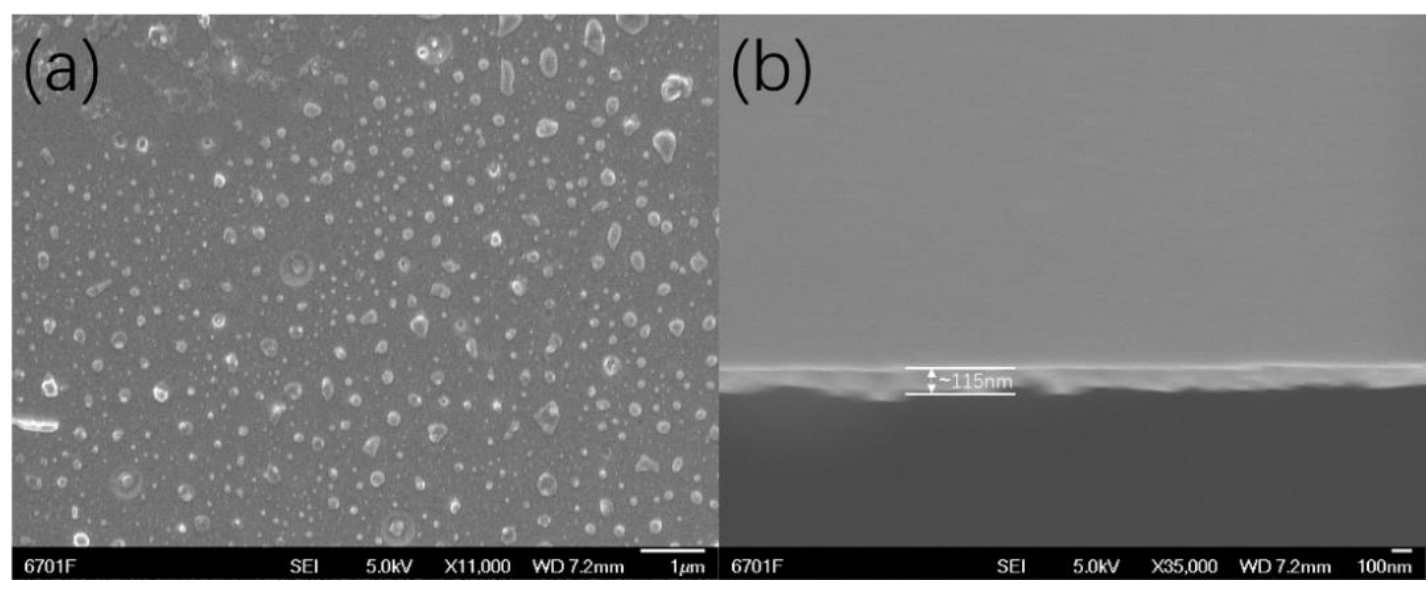

Figure S4. The SEM of hybrid omniphobic coating surface (a) and cross profile (b). There are many nano dots appearance on the coating surface that consistent with AFM results. The thickness of coating is about $115 \mathrm{~nm}$ from the SEM of cross profile.
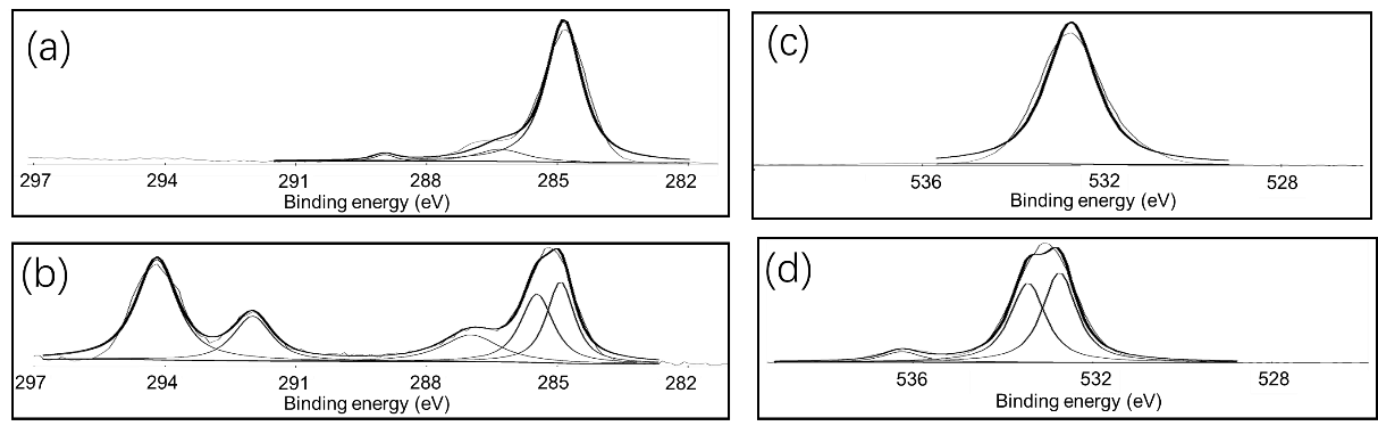

Figure S5. The fine spectra of C element before (a) and after (b) covering the hybrid coating, the fine spectra of $\mathrm{O}$ element before(c) and after (d) covering the hybrid coating. 
Table S1. The summary of contact angle and sliding angle of differs liquid on the hybrid omniphobic coating.

\begin{tabular}{|l|r|r|c|}
\hline Liquid & Surface tension & Contact angle & Sliding angle \\
\hline Water & 72.3 & 108 & 45 \\
\hline Glycerol & 64 & 103 & 60 \\
\hline Diiodomethane & 50.8 & 90 & 18 \\
\hline Glycol & 47.7 & 97 & 22 \\
\hline DMF & 37.1 & 80 & 20 \\
\hline Rap oil & 35 & 80 & 45 \\
\hline Xylene & 28.9 & 68 & 28 \\
\hline Methylbenzene & 28.4 & 66 & 23 \\
\hline Dichloromethane & 26.5 & 61 & 12 \\
\hline Tetrahydrofuran & 26.4 & 63 & 22 \\
\hline Ethyl acetate & 23.9 & 55 & 15 \\
\hline n-decane & 23.8 & 57 & 21 \\
\hline Isopropanol & 23 & 52 & 18 \\
\hline Methanol & 22.7 & 61 & 18 \\
\hline Ethanol & 22.1 & 55 & 14 \\
\hline Silicone oil & 21.6 & 60 & 50 \\
\hline Octane & 18.4 & 46 & 27 \\
\hline n-hexane & & 28 & 19 \\
\hline & & & \\
\hline
\end{tabular}
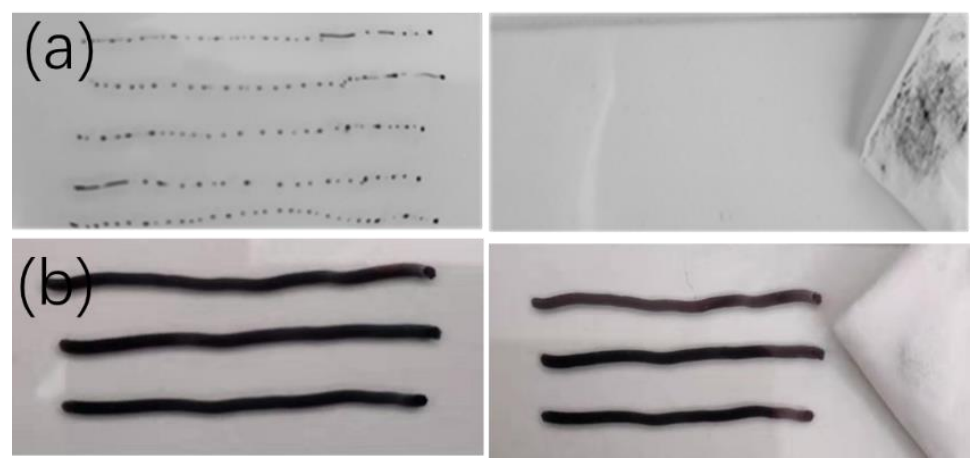

Figure S6. The trace of oily pen on the coating surface (a) and raw glass surface (b), the final state of oily pen trace after wiping with tissue paper. 

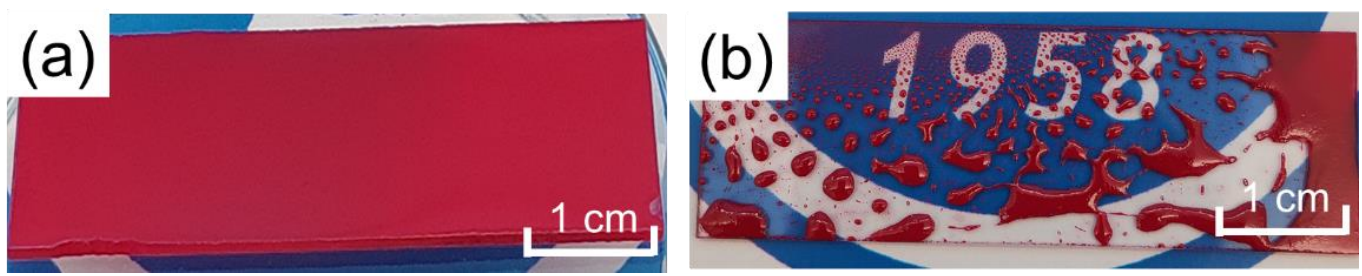

Figure S7. An oily paint sprays on (a) raw glass surface with uniform film and (b) the hybrid omniphobic coating surface with shrinkage.

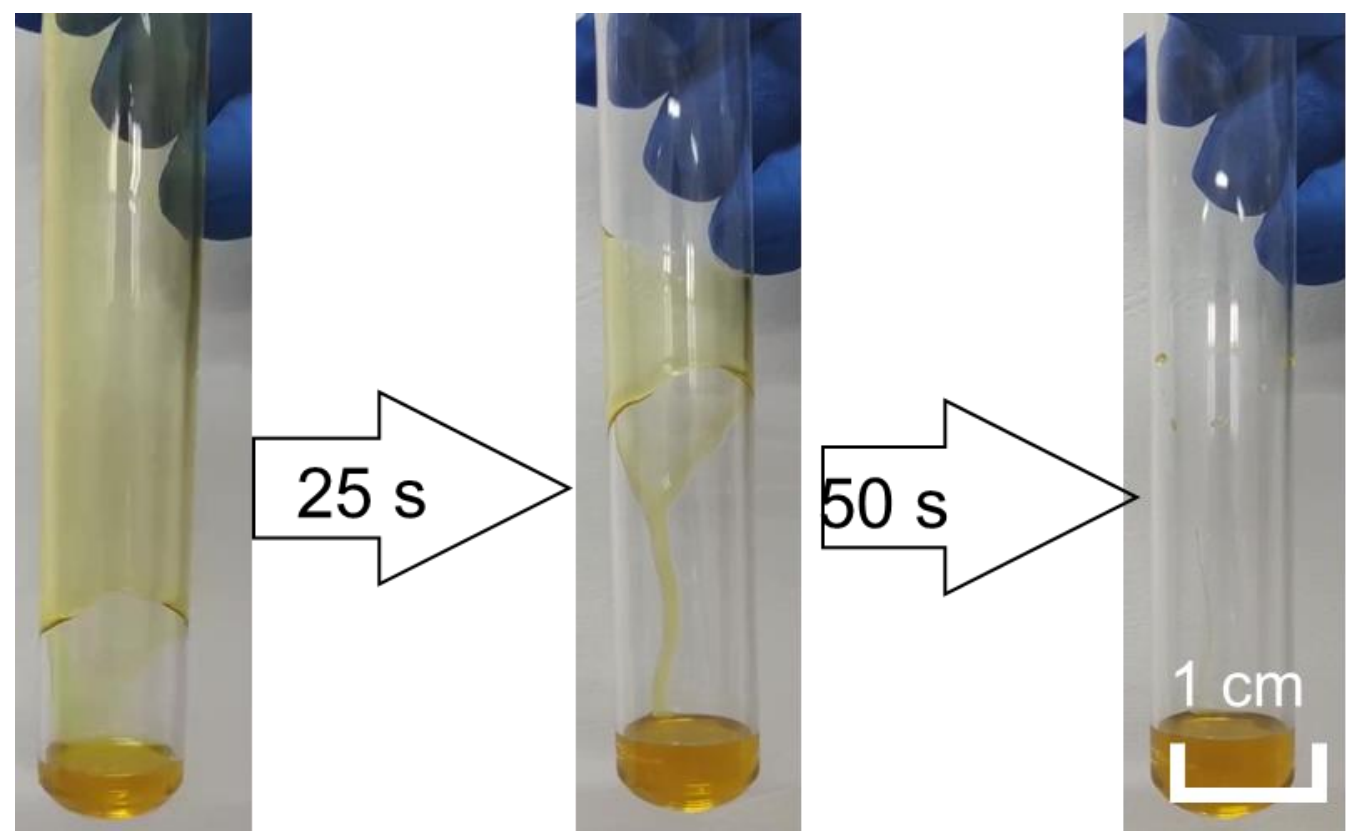

Figure S8. The omniphobic glass tube wetted by colza oil, the oil film shrank quickly and gathered at the bottom.
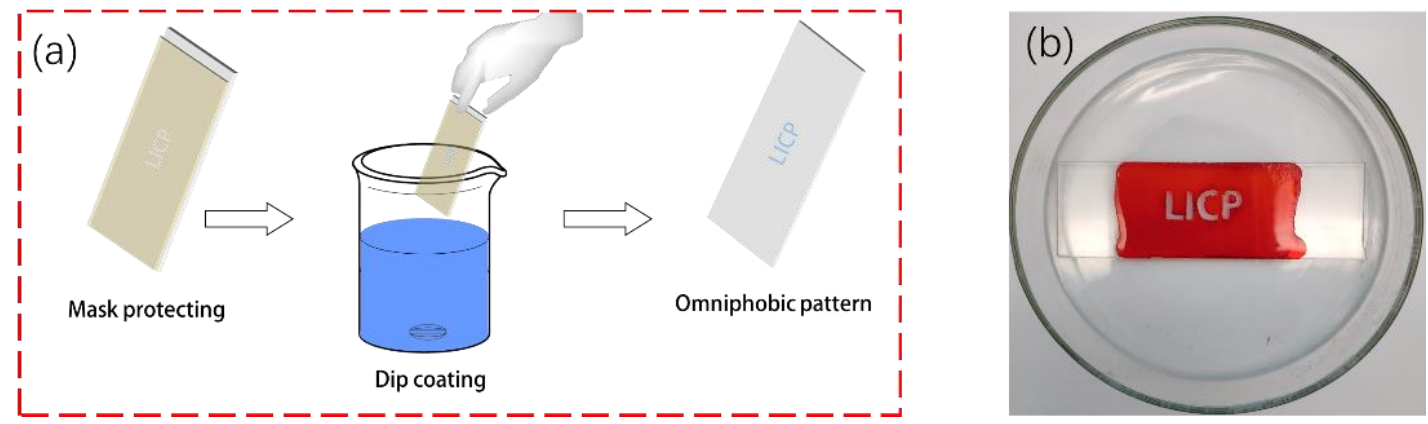

Figure S9. (a) The preparation process of omniphobic pattern on glass surface, (b) the omniphobic letter "LICP" appeared when dyed toluene dropped on the glass surface. 


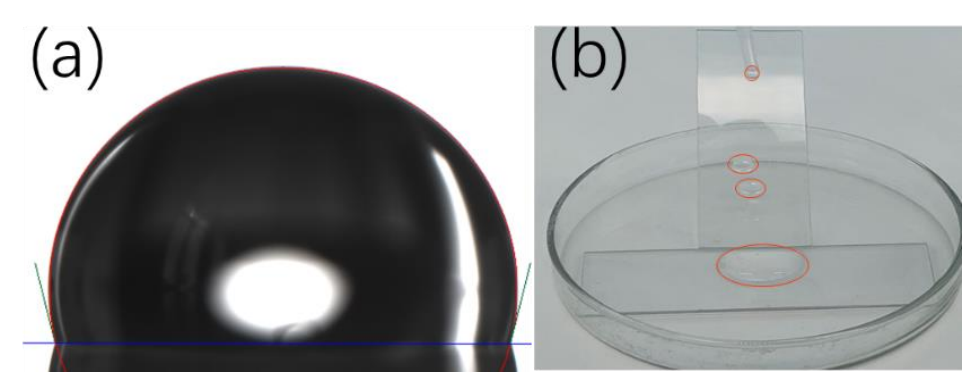

Figure S10. (a) The contact angle of synthetic perspiration on the hybrid coating, (b) the synthetic perspiration droplets can slide off from coating surface freely at a little $\operatorname{slope}\left(\sim 15^{\circ}\right)$.
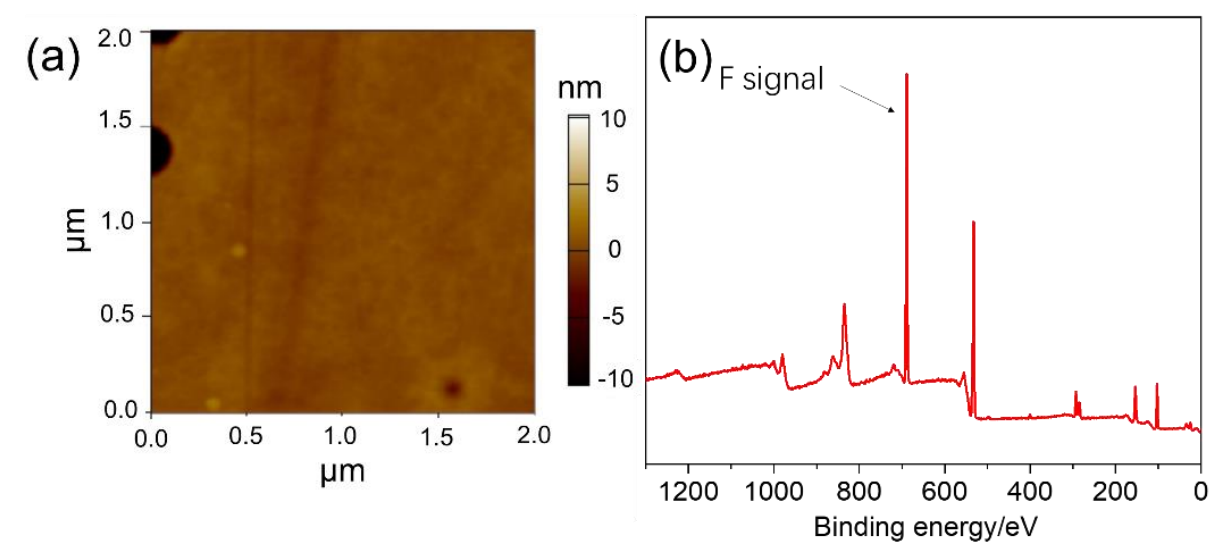

Figure S11. The AFM (a) and XPS (b) of hybrid coating after two hundred thousand friction cycles under $100 \mathrm{KPa}$.

Table S2. The element content of hybrid coating before and after two hundred thousand friction cycles under $100 \mathrm{KPa}$.

\begin{tabular}{|c|c|c|c|c|c|}
\hline Atom content (\%) & C & O & Si & F & Total \\
\hline Before wear & 28.1 & 26.1 & 14.1 & 31.7 & 100 \\
\hline After wear & 20.3 & 36.7 & 19.9 & 23.1 & 100 \\
\hline
\end{tabular}

